\title{
The NeoAPACHE Study Protocol I: Assessment of the Radiographic Pulmonary Area and Long-Term Respiratory Function in Newborns With Congenital Diaphragmatic Hernia
}

OPEN ACCESS

Edited by:

Timothy M. Maul,

Nemours Children's Hospital,

United States

Reviewed by:

Daniel Dirnberger,

Alfred I. duPont Hospital for Children,

United States

luri Corsini,

Careggi University Hospital, Italy

*Correspondence:

Giacomo Cavallaro

giacomo.cavallaro@policlinico.mi.it

Specialty section

This article was submitted to Pediatric Critical Care, a section of the journal Frontiers in Pediatrics

Received: 09 July 2020 Accepted: 08 October 2020 Published: 30 October 2020

Citation:

Amodeo I, Raffaeli G, Pesenti N, Macchini F, Condò V, Borzani I, Persico N, Fabietti I, Ophorst M, Ghirardello S, Gangi S, Colnaghi M. Mosca F and Cavallaro G (2020) The NeoAPACHE Study Protocol I: Assessment of the Radiographic Pulmonary Area and Long-Term Respiratory Function in Newborns With Congenital Diaphragmatic Hernia. Front. Pediatr. 8:581809. doi: 10.3389/fped.2020.581809

\author{
Ilaria Amodeo ${ }^{1}$, Genny Raffaeli ${ }^{1,2}$, Nicola Pesenti ${ }^{1,3}$, Francesco Macchini ${ }^{4}$, \\ Valentina Condò ${ }^{1}$, Irene Borzani ${ }^{5}$, Nicola Persico ${ }^{2,6}$, Isabella Fabietti ${ }^{6}$, Marijke Ophorst ${ }^{1}$, \\ Stefano Ghirardello ${ }^{1}$, Silvana Gangi ${ }^{1}$, Mariarosa Colnaghi ${ }^{1}$, Fabio Mosca ${ }^{1,2}$ and \\ Giacomo Cavallaro ${ }^{1 *}$ \\ ${ }^{1}$ Neonatal Intensive Care Unit (NICU), Fondazione IRCCS Ca' Granda Ospedale Maggiore Policlinico, Milan, Italy, \\ ${ }^{2}$ Department of Clinical Sciences and Community Health, Università degli Studi di Milano, Milan, Italy, ${ }^{3}$ Division of \\ Biostatistics, Epidemiology and Public Health, Department of Statistics and Quantitative Methods, University of \\ Milano-Bicocca, Milan, Italy, ${ }^{4}$ Department of Pediatric Surgery, Fondazione IRCCS Ca' Granda Ospedale Maggiore \\ Policlinico, Milan, Italy, ${ }^{5}$ Pediatric Radiology Unit, Fondazione IRCCS Ca' Granda Ospedale Maggiore Policlinico, Milan, Italy, \\ ${ }^{6}$ Department of Obstetrics and Gynecology, Fondazione IRCCS Ca' Granda, Ospedale Maggiore Policlinico, Milan, Italy
}

In newborns with congenital diaphragmatic hernia $(\mathrm{CDH})$, the radiographic lung area is correlated with functional residual capacity (FRC) and represents an alternative method to estimate lung hypoplasia. In a cohort of newborn $\mathrm{CDH}$ survivors, we retrospectively evaluated the relationship between radiographic lung area measured on the 1st day of life and long-term respiratory function. As a secondary analysis, we compared radiographic lung areas and respiratory function between patients undergoing fetal endoscopic tracheal occlusion (FETO) and patients managed expectantly (non-FETO). Total, ipsilateral, and contralateral radiographic areas were obtained by tracing lung perimeter as delineated by the diaphragm and rib cage, excluding mediastinal structures and herniated organs. Tidal volume $\left(V_{T}\right)$, respiratory rate $(R R)$, and their Z-Scores when compared to the norm were collected from pulmonary function tests (PFTs) performed at $12 \pm 6$ months of age. Linear regression analyses using the absolute Z-Score values for each parameter were performed. In CDH survivors, an increase in total and ipsilateral lung area measured at birth was related to a reduction in the absolute Z-Score for $V_{T}$ in PFTs $(p=0.046$ and $p=0.023$, respectively), indicating a trend toward an improvement in pulmonary volumes and $\mathrm{V}_{\mathrm{T}}$ normalization. Radiographic lung areas were not significantly different between FETO and non-FETO patients, suggesting a volumetric lung increase due to prenatal intervention. However, the mean Z-Score value for RR was significantly higher in the FETO group $(p<0.001)$, probably due to impaired diaphragmatic motility 
in the most severe cases. Further analyses are necessary to better characterize the role of the radiographic pulmonary area in the prognostic evaluation of respiratory function in patients with $\mathrm{CDH}$.

Clinical Trial Registration: This trial was registered at ClinicalTrials.gov with the identifier NCT04396028.

Keywords: congenital diaphragmatic hernia, radiographic lung area, lung hypoplasia, FETO, respiratory function tests, neonatology, long term respiratory function

\section{INTRODUCTION}

Congenital diaphragmatic hernia $(\mathrm{CDH})$ is a severe malformation characterized by a diaphragm defect associated with herniation of the abdominal organs into the thoracic cavity. The resulting early impairment of lung development leads to decreased bronchial branching and smaller alveolar exchange surface area, as well as to a reduction and remodeling of the vascular system (1). After birth, pulmonary hypoplasia and persistent pulmonary hypertension determine severe respiratory compromise, and both play a key role in long-term morbidity among surviving patients (1-4).

Measuring functional residual capacity (FRC) through body plethysmography or the gas dilution technique represent the gold standard to assess lung volumes during infancy (5-8). However, these assessments are extremely complex to be performed in the 1 st months of life and are not always readily available in some centers $(8,9)$. These limitations have led researchers to develop more straightforward methods to estimate lung volumes and lung hypoplasia in newborn patients.

Measured radiographic lung area has shown a significant positive correlation with FRC in neonates receiving intensive care as well as with the risk of extubation failure in preterm newborns $(8,9)$. A significant correlation has also been reported between measured pulmonary area and disease severity and oxygenation capacity in premature infants with bronchopulmonary dysplasia (BPD) $(10,11)$. Furthermore, this method has been applied to newborns with $\mathrm{CDH}$, showing a statistically significant relationship between the radiographic lung area, acquired both pre- and postoperatively, and FRC measured through the diluted helium technique (12).

Therefore, measuring the radiographic lung area could be considered a reliable method to assess lung hypoplasia in $\mathrm{CDH}$ patients $(12,13)$. However, the potential relationship between radiographic lung area and other aspects of the respiratory function has never been explored in this population.

Since the herniated organs compromise lung development as a whole, changes in the radiographic lung area, tidal volume $\left(V_{T}\right)$, and respiratory rate (RR) could be strictly related to each other.

This study aimed to investigate a possible relationship between radiographic pulmonary area measured on the 1st day of life and respiratory function at 1 year of age in a cohort of patients with $\mathrm{CDH}$. As secondary aim, it also aimed to describe the pulmonary radiological and functional features in patients undergoing fetal endoscopic tracheal occlusion (FETO) and to compare them to untreated patients, as well as to investigate the relationship between lung area and PFTs in these two groups. According to our hypothesis, a larger lung area would allow patients to show a better performance in pulmonary function tests (PFTs) during follow-up.

\section{MATERIALS AND METHODS}

This study is part of an observational retrospective cohort study aimed at Assessing the Pulmonary Area in newborns with Congenital diaphragmatic Hernia (NeoAPACHE). The study was performed at the Neonatal Intensive Care Unit (NICU) of the Fondazione IRCCS Ca' Granda Ospedale Maggiore Policlinico, Milan, Italy, on a cohort of $\mathrm{CDH}$ patients over a 6-year period (January 2012-December 2018).

\section{Subjects}

Inborn and outborn neonates with $\mathrm{CDH}$ born between January 2012 and December 2018 were considered for the study. Patients were enrolled according to the following criteria:

Inclusion criteria (all of these):

- Inborn and outborn patients admitted to the NICU within $24 \mathrm{~h}$ after birth

- Prenatal or postnatal (within $24 \mathrm{~h}$ of birth) diagnosis of $\mathrm{CDH}$

- Preoperative, clinically indicated chest radiograph performed within $24 \mathrm{~h}$ of birth in our NICU

Exclusion criteria (one of these):

- Preoperative chest radiographs that were rotated/asymmetric, presented air leak (e.g., pneumothorax or pneumoperitoneum), were not performed in our NICU, or were not available.

- Early death (within $1 \mathrm{~h}$ of birth).

Fetal intervention at our Fetal Surgery Center was considered according to the combined evaluation of the observed/expected lung-to-head ratio (O/E LHR\%), liver herniation, and side of the diaphragmatic defect (i.e., left, right, or bilateral). FETO procedure was offered to fetuses with severe lung hypoplasia, defined as an O/E LHR $<25 \%$ and $<45 \%$ in left and right $\mathrm{CDH}$, respectively, in the absence of major associated malformations and/or genetic anomalies known to have a significant impact on postnatal survival (14). Since 2016, our Center has been recruiting patients with moderate and severe left $\mathrm{CDH}$ in a multicenter randomized clinical trial (www.totaltrial. 
eu). Patients included and randomized in the aforementioned trial were not included in the present study.

All $\mathrm{CDH}$ patients admitted to our NICU are managed according to the CDH EURO Consortium Consensus (15). After discharge, all patients are included in a follow-up program done by a multidisciplinary team, including neonatologists, pediatric surgeons, pneumologists, and lung function technicians $(4,16)$.

\section{Assessment of the Radiographic Pulmonary Area}

Two operators (a neonatologist and a pediatric radiologist) independently reviewed all preoperative digital radiographs performed within the first $24 \mathrm{~h}$ of life using the Synapse PACS (Fujifilm Italia SPA) software. All chest X-rays were taken in an anteroposterior projection, with the patient in a supine position, at a standard distance of $1 \mathrm{~m}$ above the patient, and at the end of inspiration. The radiograph that showed the most lung recruitment was selected for each enrolled patient. Pulmonary area was then assessed by freehand tracing of the perimeter of the thoracic area as outlined by the diaphragm and the rib cage, excluding the herniated abdominal contents and mediastinal structures (Figures 1A,B). Only the aerated portions of the lungs were considered. The corresponding areas were automatically calculated by the Synapse PACS (Fujifilm Italia SPA) software. On each selected radiograph, the following three measures were taken:

1. Ipsilateral pulmonary area $\left(\mathrm{cm}^{2}\right)$

2. Contralateral pulmonary area $\left(\mathrm{cm}^{2}\right)$

3. Total pulmonary area $\left(\mathrm{cm}^{2}\right)$, derived from the sum of the preceding two.

\section{Data Collection}

Data regarding prenatal history, clinical course, and postnatal surgical course were collected from the medical records of each patient. In the 1st year of life, recurrence after surgical repair and number of deceased infants were recorded. Data concerning clinical and instrumental follow-up were also collected. All data was anonymized.

\section{Pulmonary Function Tests}

All PFTs performed during spontaneous sleeping at the age of 1 year (range 6-18 months) were reviewed (Exhalyzer ${ }^{\circledR} \mathrm{D}$, Ecomedics, Dürnten, Switzerland). Clinical data, such as age, weight, length, $\mathrm{V}_{\mathrm{T}}$, and $\mathrm{RR}$, were recorded. The predicted normal values of $V_{T}$ and $R R$ were then calculated using the reference equations for healthy children (17). Age was corrected for prematurity in preterm infants. Finally, Z-Scores for $\mathrm{V}_{\mathrm{T}}$ and RR were calculated to express how much the observed values deviated from the expected normal values in terms of standard deviation. When calculating the normal values and Z-Scores, the patient's weight, length, and age were included (17).

\section{Statistical Analysis}

Continuous variables are reported as means (standard deviation) or medians (interquartile range); categorical variables are presented as numbers and percentages. For the comparison between groups, the Student's $t$-test, Mann-Whitney $U$-test, or Fisher exact test were used as appropriate.

The agreement between the lung area measurements performed by the two operators was evaluated using the Bland-Altman plot and by calculating the Pearson Correlation index. For subsequent analysis, only measurements done by the neonatologist were considered.

The relationship between $V_{T}$ and $R R$ and the effects of the lung area at birth on respiratory function at 1 year of life were analyzed through a linear regression model. For the latter, the absolute values of $\mathrm{V}_{\mathrm{T}}$ and $\mathrm{RR} \mathrm{Z}$-Scores were used, as we were interested in observing either the positive or negative changes in the absolute Z-Score taking as reference the mean expected

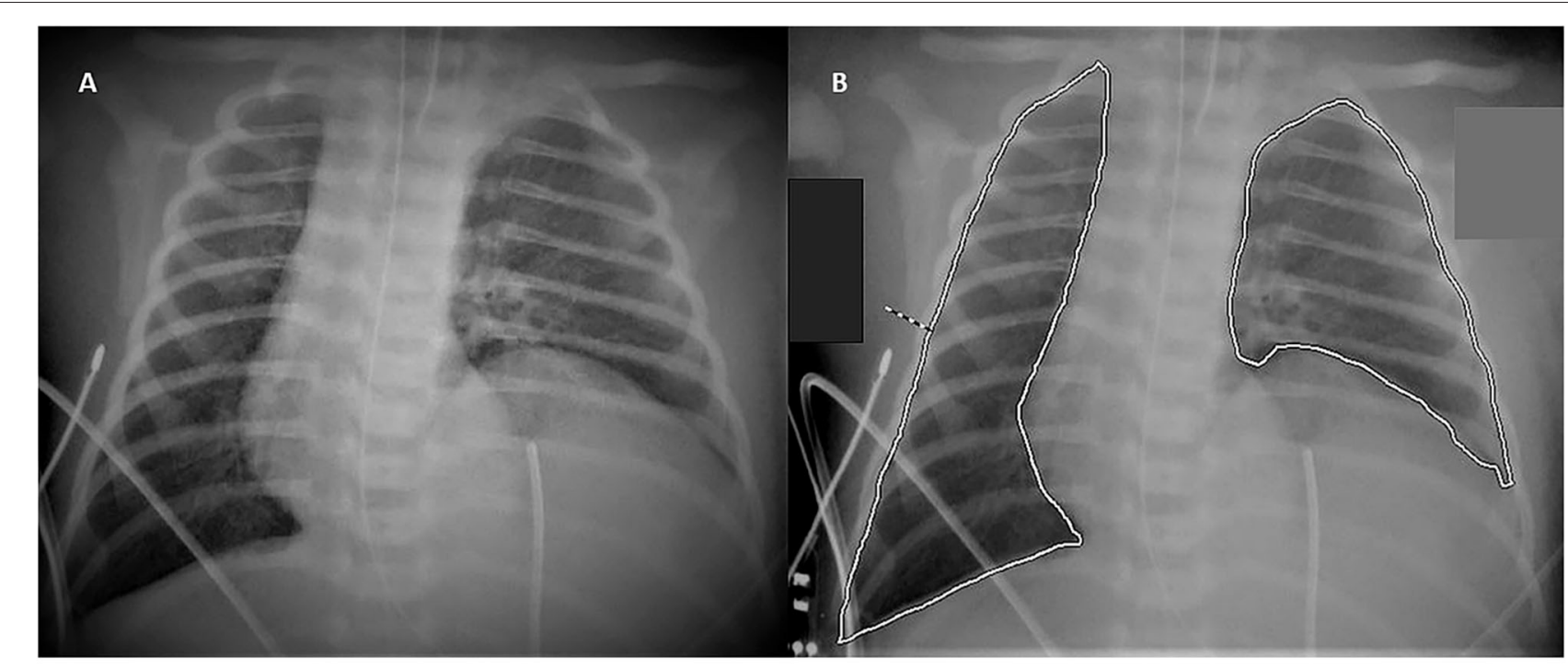

FIGURE 1 | Tracing Method. The figure shows the method to calculate the area of the lungs: chest radiograph of a 1-day-old infant without (A) and with (B) the freehand tracing of the perimeter of the lungs. 
normal value, which was represented by zero. The results of the regression models were corrected for gestational age and accounted for prematurity and corrected age at the time of PFTs as well as the difference between the observed $\mathrm{V}_{\mathrm{T}}$ and the mean normal value expected for each patient $\left(Z\right.$-Score $\left.V_{T}\right)$, whose calculation also included anthropometric variables (17). Statistical analysis was performed using IBM SPSS Statistics v26.0 (IBM Corp. Armonk, NY, USA). A $p$-value of 0.05 or lower was considered to be statistically significant.

\section{Ethical Considerations}

The present study was carried out in accordance with the principles of good clinical practice and the Helsinki Declaration, as well as the national legislative and administrative provisions in force. This study was approved by the local Ethics Committee (Milan Area 2, Italy) with approval number OSMAMI04/05/2020-0015998-U.

\section{RESULTS}

From January 2012 to December 2018, a total of 86 patients with congenital diaphragmatic hernia were managed in our NICU and were eligible for the study (Figure 2). However, nine patients did not meet the inclusion criteria and were excluded from the assessment of their radiographic pulmonary area, which was performed for 77 patients.

Fifty-one patients survived until discharge from our NICU, while 26 patients died during their hospital stay. Furthermore, another patient died a few weeks after being discharged from the NICU. For six patients, PFTs were missing; in one case, they were performed before the age of 6 months. Thus, a total of 43 patients underwent PFTs between 6 and 18 months of life and constituted the follow-up group.

Demographic, antenatal, postnatal surgical, and clinical characteristics of the 43 follow-up patients are summarized in Table 1. The study population included infants born at term $(37.2 \pm 1.9$ weeks of gestational age) with adequate birth weight $(2,946 \pm 567 \mathrm{~g})$. CDH was mostly mild and left-sided with a liver herniation prevalence of $48.8 \%$. The median time for the surgical repair procedure was during the 2 nd day of life, and a diaphragmatic patch was required in 18 (41.9\%) patients (Table 1).

\section{Reproducibility of the Radiographic Measurements}

Pulmonary area was independently assessed by the two operators for all enrolled patients. The mean total pulmonary area on the 1st day of life was $12.5 \pm 7$ and $12.6 \pm 7 \mathrm{~cm}^{2}$ when measured by the neonatologist and the pediatric radiologist, respectively. As shown by the Bland-Altman plot, the mean of the differences between the measurements of the two operators was $0.055 \mathrm{~cm}^{2}$ with $95 \%$ Limits of Agreement between -1.14; $1.25 \mathrm{~cm}^{2}$ (Figure 3). The Pearson correlation coefficient was 0.99 $(p<0.001)$, corresponding to a high level of agreement between both operators.

\section{Pulmonary Area and Respiratory Function}

In the follow-up population, the mean total pulmonary area measured on the 1st day of life was $14.9 \pm 6.3 \mathrm{~cm}^{2}$, with a mean ipsilateral pulmonary area of $5.1 \pm 3.1 \mathrm{~cm}^{2}$ and a mean contralateral pulmonary area of $9.8 \pm 3.8 \mathrm{~cm}^{2}$ (Table $\mathbf{1}$ ).

PFTs were performed at a mean age of $10.7 \pm 3.2$ months. The mean $\mathrm{Z}$-Score $\mathrm{V}_{\mathrm{T}}$ was $-2.9 \pm 2.5$, and the mean $\mathrm{Z}$-Score $\mathrm{RR}$ was $1.3 \pm 3.6$ (Table $\mathbf{1}$ ). When a linear regression analysis was performed on these data, changes in these two parameters were inversely related $(\mathrm{B}-0.9 ; 95 \% \mathrm{CI}-1.26,-0.55 ; p<0.001)$ (Figure 4).

In order to evaluate the relationship between pulmonary area and $\mathrm{V}_{\mathrm{T}}$ or $\mathrm{RR}$, the absolute values of $\mathrm{Z}$-Score $\mathrm{V}_{\mathrm{T}}$ and $\mathrm{Z}$-Score $\mathrm{RR}$ were considered. Following a linear regression model, the total and ipsilateral lung area were significantly related to the absolute value of Z-Score $\mathrm{V}_{\mathrm{T}}$. The contralateral lung area did not appear to have a relationship with the absolute value of $Z$-Score $V_{T}$. Finally, no relationship was found between the radiographic parameters and the absolute values of Z-Score RR (Table 2).

\section{Comparison Between FETO and Non-FETO Patients}

In the follow-up population, the FETO procedure had been performed in 11 out of 43 patients (25.6\%), while 32 patients had not been treated. A comparison of demographics, prenatal history, postnatal clinical, and surgical characteristics between the two groups is shown in Table 3.

In the FETO group, patients had a mean gestational age of $35.7 \pm 2.5$ weeks and a mean birth weight of $2,616 \pm 465 \mathrm{~g}$, while the non-FETO group had a mean gestational age of $37.7 \pm 1.4$ weeks and a mean birth weight of $3,059 \pm 560 \mathrm{~g}(p=0.003$ and $p$ $=0.023$, respectively). In the FETO group, the mean initial $\mathrm{O} / \mathrm{E}$ LHR was $27.2 \pm 5.8 \%$ and the mean final O/E LHR was $67.2 \pm$ $11.3 \%$, both significantly different from non-FETO group (initial O/E LHR $47 \pm 11.2 \%, p<0.001$; final O/E LHR $52.5 \pm 13.5 \%, p$ $=0.004)$.

Radiographs taken preoperatively on the 1st day of life did not show any statistical difference in the mean total, ipsilateral, or contralateral pulmonary areas between the FETO group and the non-FETO (total area: $13.4 \pm 6.3$ vs. $15.5 \pm 6.3 \mathrm{~cm}^{2}, p=$ 0.358 ; ipsilateral area: $4.6 \pm 3.2$ vs. $5.3 \pm 3.1 \mathrm{~cm}^{2}, p=0.553$; contralateral area: $8.8 \pm 3.9$ vs. $\left.10.2 \pm 3.8 \mathrm{~cm}^{2}, p=0.306\right)$. (Figures 5A-C).

PFTs were performed at a mean age of $9.7 \pm 2.8$ months in the FETO group and $11 \pm 3.3$ months in the non-FETO group $(p=0.274)$. The mean Z-Score RR was significantly higher in the FETO group $(4.5 \pm 3.8)$ when compared to the non-FETO group $(0.2 \pm 2.7, p<0.001)$. There was also a difference between the FETO and non-FETO groups regarding Z-Score $\mathrm{V}_{\mathrm{T}}(-4 \pm 2$ vs. $-2.5 \pm 2.5)$, though it was not statistically significant $(p=0.070)$ (Figures 6A,B).

Using the absolute values of $\mathrm{Z}$-Score $\mathrm{V}_{\mathrm{T}}$ and $\mathrm{Z}$-Score $\mathrm{RR}$, linear regression analysis was performed to investigate the possible relationship between respiratory and radiological parameters (Table 4). Only in the non-FETO group, a significant relationship was confirmed between the total pulmonary area 


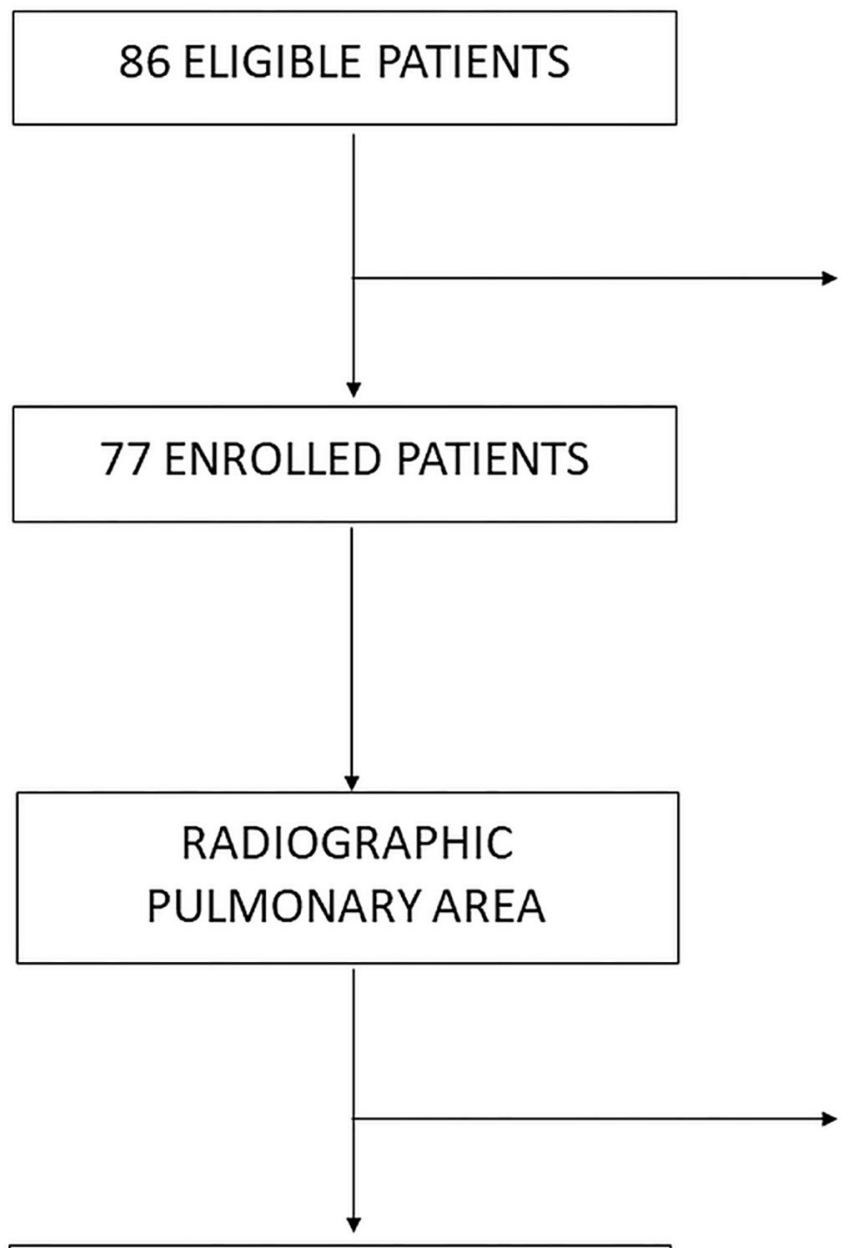

EXCLUDED:

4 outborn admitted $>24$ hours of life

2 diagnosis $>24$ hours of life

1 pneumoperitoneum

1 missing data

1 death at 40 minutes of life

EXCLUDED:

26 deaths during hospital stay

51 DISCHARGED PATIENTS

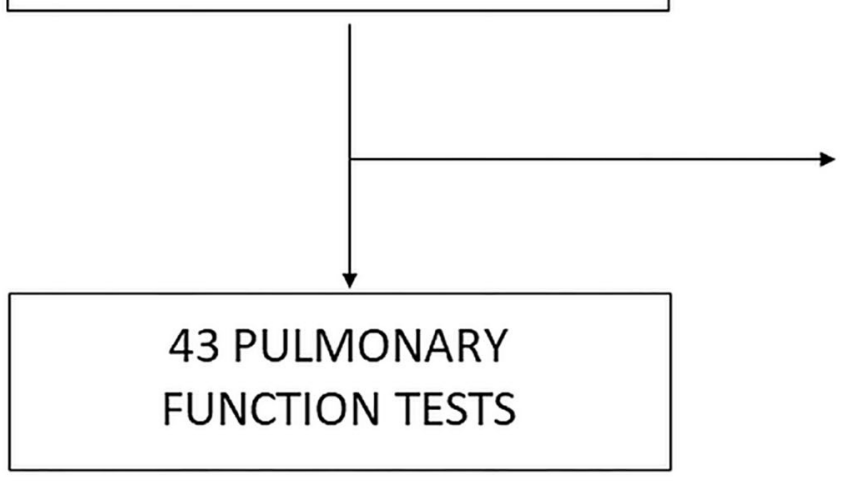

EXCLUDED:

1 death after discharge

6 missing tests

1 test before 6 months of life

FIGURE 2 | Study Flowchart.

and the absolute Z-Score $\mathrm{V}_{\mathrm{T}}(\mathrm{B}-0.11 ; 95 \% \mathrm{CI}-0.21,0 ; p=$ 0.045 ), while no statistical significance was found for the other two radiological parameters. The absolute Z-Score RR did not show any significant relationships either. In the FETO group, no relationship between radiological lung area at birth and respiratory parameters at 1 year of follow-up was demonstrated. 
TABLE 1 | Characteristics of the follow-up population.

Follow-up patients $(n=43)$

\begin{tabular}{|c|c|}
\hline \multicolumn{2}{|l|}{ PRENATAL DATA } \\
\hline \multicolumn{2}{|l|}{ Side of the defect - $n(\%)$} \\
\hline $\begin{array}{l}\text { - Left CDH } \\
\text { - Right CDH }\end{array}$ & $\begin{array}{c}35(81.4) \\
8(18.6)\end{array}$ \\
\hline FETO - n (\%) & $11(25.6)$ \\
\hline \multicolumn{2}{|l|}{ O/E LHR\% - mean ( \pm SD) } \\
\hline $\begin{array}{l}- \text { Initial } \\
-\quad \text { Final }\end{array}$ & $\begin{array}{l}40.4(13.5) \\
56.6(14.4)\end{array}$ \\
\hline \multicolumn{2}{|l|}{ Grading CDH - $n(\%)$} \\
\hline $\begin{array}{l}\text { - Severe } \\
\text { - Moderate } \\
\text { - Mild }\end{array}$ & $\begin{array}{c}11(25.6) \\
5(11.6) \\
27(62.8)\end{array}$ \\
\hline Liver UP - $n(\%)$ & $21(48.8)$ \\
\hline Stomach UP - $n(\%)$ & $25(58.1)$ \\
\hline Spleen UP - $n(\%)$ & $27(62.8)$ \\
\hline \multicolumn{2}{|l|}{ POSTNATAL DATA } \\
\hline Gestational age (weeks) - mean (SD) & $37.2(1.9)$ \\
\hline Birthweight (g) - mean (SD) & $2,946(567)$ \\
\hline Males - $n(\%)$ & $28(65.1)$ \\
\hline Inborn - $n(\%)$ & $40(93)$ \\
\hline Vaginal delivery - $n(\%)$ & $27(62.8)$ \\
\hline APGAR 1 min - median (IQR) & $6(4.5-8)$ \\
\hline APGAR 5 min - median (IQR) & $8(8-9)$ \\
\hline Day of surgical repair - median (IQR) & $2(2-3)$ \\
\hline Diaphragmatic patch - $n(\%)$ & $18(41.9)$ \\
\hline Abdominal patch - $n(\%)$ & $1(2.3)$ \\
\hline Mechanical ventilation (days) - median (IQR) & $16(10-20)$ \\
\hline ECMO - $n(\%)$ & $0(0)$ \\
\hline Length of stay (days) - median (IQR) & $44(33-70)$ \\
\hline \multicolumn{2}{|l|}{ RADIOGRAPHIC PULMONARY AREA } \\
\hline Total pulmonary area $\left(\mathrm{cm}^{2}\right)$ - mean (SD) & $14.9(6.3)$ \\
\hline Ipsilateral pulmonary area $\left(\mathrm{cm}^{2}\right)$ - mean (SD) & $5.1(3.1)$ \\
\hline Contralateral pulmonary area $\left(\mathrm{cm}^{2}\right)$ - mean (SD) & $9.8(3.8)$ \\
\hline \multicolumn{2}{|l|}{ PULMONARY FUNCTION TESTS } \\
\hline Age corrected for prematurity (months) - mean (SD) & $10.7(3.2)$ \\
\hline Weight (kg) - mean (SD) & $8.4(1.3)$ \\
\hline Z-Score Tidal Volume - mean (SD) & $-2.9(2.5)$ \\
\hline Z-Score Respiratory Rate - mean (SD) & $1.3(3.6)$ \\
\hline
\end{tabular}

$C D H$, congenital diaphragmatic hernia; FETO, fetal endoscopic tracheal occlusion; O/E $L H R$, observed/expected lung-to-head ratio; SD, standard deviation; IQR, interquartile range; ECMO, extracorporeal membrane oxygenation.

\section{DISCUSSION}

To the best of our knowledge, this is the first study to address the role of radiographic lung area in evaluating long-term respiratory function in newborns with $\mathrm{CDH}$. Our study demonstrated an association between the radiographic pulmonary area measured on the 1st day of life and $\mathrm{V}_{\mathrm{T}}$ assessed at follow-up it this population. Our findings suggest that the use of the radiographic pulmonary area is an easy, fast, and non-invasive predictive tool for assessing long-term respiratory morbidity in neonates with CHD.

In the last decade, improvements in fetal surgery and neonatal intensive care, new "gentle" ventilation approaches, and ECMO support have permitted an increase in survival rates of $\mathrm{CDH}$ patients, especially those with severe disease (4, 18-20). Moreover, these improved survival rates have inevitably increased associated respiratory morbidity, requiring multidisciplinary long-term follow-up (4).

The gold standard techniques to assess lung volumes (e.g., plethysmography and gas dilution) are challenging to be performed in the 1st months of life, while the lung area is highly reproducible and can be performed by every operator $(8,10-13)$, as our interrater assessments results show.

\section{Pulmonary Area and Respiratory Function}

The pulmonary function in $\mathrm{CDH}$ infants in the 1st months after surgery is often characterized by decreased lung volumes, reduced compliance, and increased respiratory rate (21-24). Our data confirm that $\mathrm{CDH}$ survivors show a tendency toward low tidal volumes associated with normal or high respiratory rates. This trend could be explained by the presence of lung hypoplasia associated with impaired diaphragmatic function, which could be the result of the malformation itself combined with the consequences of surgical repair. Arena et al. reported that, even several years after surgery, motility of the repaired hemidiaphragm was reduced when compared with the contralateral side or with healthy controls (25). Furthermore, Laviola et al. confirmed these results and demonstrated that patients undergoing patch repair showed the most significant motility impairment, partially compensated by the contribution of the inspiratory rib cage muscles (26). Moreover, the relationship between the diaphragm and the chest wall was altered, with marked asynchronies and asymmetries during inspiration between the thorax and the abdomen and between the left and right sides of the thorax (26). Recently, decreased diaphragmatic strength and endurance in the neonatal period were demonstrated by Khirani et al., showing an improving trend during the first 5 years of life (27).

Regarding the $\mathrm{V}_{\mathrm{T}}$ analysis in $\mathrm{CDH}$ survivors, as the pulmonary area increased, the absolute value of Z-Score $V_{T}$ tended to decrease, meaning that it approximated the expected standard value. These findings are in accordance with the existing evidence that radiographic lung area correlates with the degree of pulmonary hypoplasia, and also further provides evidence on the association between better lung development, higher radiographic areas, and improved ventilation.

The most robust relationship with $\mathrm{V}_{\mathrm{T}}$ was found for the ipsilateral pulmonary area and second for the total pulmonary area, which is directly influenced by the former. Indeed, the lung ipsilateral to the diaphragmatic defect is the most compromised in fetuses and newborns with $\mathrm{CDH}$, mainly determining the respiratory outcomes. Nevertheless, the contralateral lung also plays a key role in compensating for the patient's respiratory function and in contributing to the long-term outcome (1). 


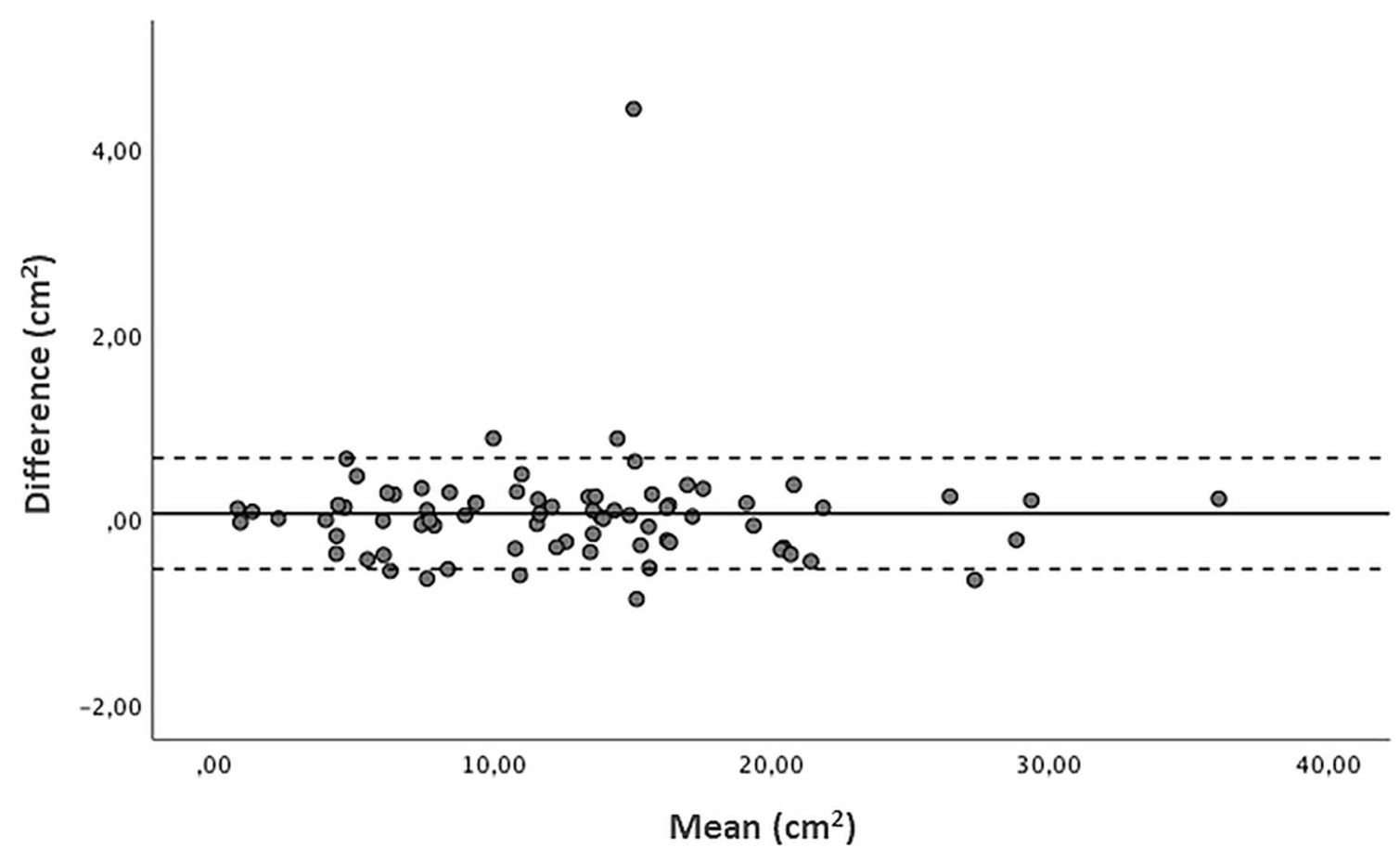

FIGURE 3 | Bland Altman plot of radiographic pulmonary area $\left(\mathrm{cm}^{2}\right)$ : difference vs. average values measured by the two operators, with $95 \%$ limits of agreement. Mean of the differences $0.055 \mathrm{~cm}^{2}, 95 \%$ Limits of Agreement $-1.14 ; 1.25 \mathrm{~cm}^{2}$.

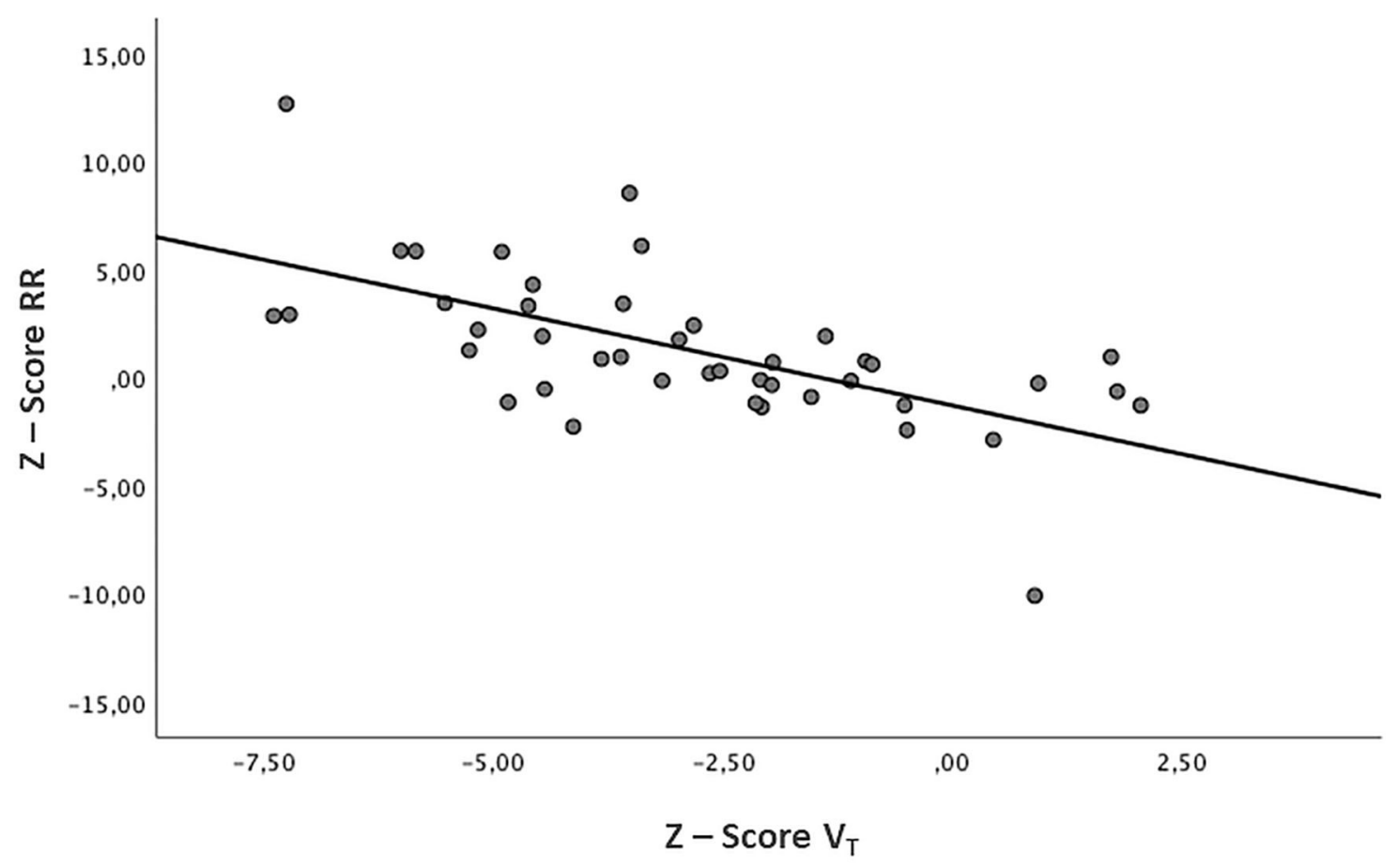

FIGURE 4 | Relation between $V_{T}$ and RR. Z-Score Tidal Volume $\left(V_{T}\right)$ and $Z$-Score Respiratory Rate (RR) show an inverse relationship $(B-0.9, p<0.001)$. 
TABLE 2 | Linear regression analysis between radiographic measurements and absolute Z-Score Tidal Volume $\left(\mathrm{V}_{\mathrm{T}}\right)$ or absolute Z-Score Respiratory Rate $(\mathrm{RR})$ in the follow-up population $(n=43)$.

\begin{tabular}{|c|c|c|c|c|c|c|}
\hline \multirow[t]{2}{*}{ Follow-up } & \multicolumn{3}{|c|}{ Absolute Z-score VT } & \multicolumn{3}{|c|}{ Absolute Z-score RR } \\
\hline & B & $95 \% \mathrm{Cl}$ & $p$-value & B & $95 \% \mathrm{Cl}$ & $p$-value \\
\hline $\begin{array}{l}\text { Total pulmonary area } \\
\left(\mathrm{cm}^{2}\right)\end{array}$ & -0.10 & $\begin{array}{c}-0.19 \\
0.00\end{array}$ & 0.046 & -0.05 & $\begin{array}{c}-0.19 \\
0.09\end{array}$ & 0.459 \\
\hline $\begin{array}{l}\text { Ipsilateral pulmonary } \\
\text { area }\left(\mathrm{cm}^{2}\right)\end{array}$ & -0.22 & $\begin{array}{l}-0.40 \\
-0.03\end{array}$ & 0.023 & -0.21 & $\begin{array}{c}-0.48 \\
0.07\end{array}$ & 0.135 \\
\hline $\begin{array}{l}\text { Contralateral } \\
\text { pulmonary area }\left(\mathrm{cm}^{2}\right)\end{array}$ & -0.11 & $\begin{array}{c}-0.27 \\
0.04\end{array}$ & 0.154 & 0.00 & $\begin{array}{c}-0.23 \\
0.23\end{array}$ & 0.989 \\
\hline
\end{tabular}

Contrary to these results, we did not find any significant relationship between radiographic pulmonary area at birth and respiratory rate at follow-up.

\section{Comparison Between FETO and Non-FETO Patients}

As an additional analysis, we focused on the comparison between FETO and non-FETO groups of patients. The first group was characterized by more severe forms of $\mathrm{CDH}$, as shown by a lower mean O/E LHR\% at diagnosis and a 100\% rate of liver herniation. The discrepancy observed in mean gestational age and birth weight is consistent with literature data, which reports preterm birth as the main fetal-maternal complication related to the prenatal procedure (14). After birth, the broader use of the patch for surgical repair indicated the presence of large defects, which could justify a greater diaphragmatic motility impairment and a higher RR in this subgroup. A significant increase in the RR of FETO patients during the first 6-12 months of life has also been recently highlighted by Morandi et al., who suggested that increased anatomical dead space due to procedure-related tracheomegaly could contribute to this trend. At 18 months of age, presumably due to catch-up growth and lung maturation, this difference with untreated patients tended to disappear (28). Several published studies agree with an improvement of lung function during infancy, though the actual timing of developmental changes remains controversial $(22,24,27,29,30)$.

Despite a more severe initial clinical status, the radiographic pulmonary areas measured on the 1st day of life did not significantly differ between FETO and non-FETO patients who survived, similar to the results of a report by Dassios et al. (13). In line with evidence in the literature, our findings reflect the excellent response to prenatal treatment in promoting lung development and counteracting the onset of lung hypoplasia. In our cohort, this led to a better final O/E LHR\% when compared to expectantly managed fetuses $(14,15)$. We did not find a significant difference in the $\mathrm{Z}$-Score $\mathrm{V}_{\mathrm{T}}$ values measured at an equivalent postnatal age between the two groups. However, FETO patients showed a more negative mean Z-Score $V_{T}$, which means that the observed tidal volume generally deviated from the normal expected value more so than what was observed in
TABLE 3 | Comparison of the characteristics between FETO and non-FETO patients.

\begin{tabular}{|c|c|c|c|}
\hline & $\begin{array}{l}\text { FETO } \\
(n=11)\end{array}$ & $\begin{array}{l}\text { Non-FETO } \\
(n=32)\end{array}$ & $p$-value \\
\hline \multicolumn{4}{|l|}{ PRENATAL DATA } \\
\hline \multicolumn{4}{|l|}{ Side of the defect - $n(\%)$} \\
\hline $\begin{array}{l}\text { - Left CDH } \\
\text { - Right CDH }\end{array}$ & $\begin{array}{l}6(54.5) \\
5(45.5)\end{array}$ & $\begin{array}{c}29(90.6) \\
3(9.4)\end{array}$ & $0.017^{\wedge}$ \\
\hline \multicolumn{4}{|l|}{ O/E LHR\% - mean (SD) } \\
\hline $\begin{array}{l}\text { - Initial } \\
\text { - Final }\end{array}$ & $\begin{array}{l}27.2(5.8) \\
67.2(11.3)\end{array}$ & $\begin{array}{c}47(11.2) \\
52.5(13.5)\end{array}$ & $\begin{array}{r}<0.001^{*} \\
0.004^{\star}\end{array}$ \\
\hline \multicolumn{4}{|l|}{ Grading CDH - $n(\%)$} \\
\hline $\begin{array}{l}\text { - Severe } \\
\text { - Moderate } \\
\text { - Mild }\end{array}$ & $\begin{array}{c}11(100) \\
0(0) \\
0(0)\end{array}$ & $\begin{array}{c}0(0) \\
5(15.6) \\
27(84.4)\end{array}$ & $<0.001^{\wedge}$ \\
\hline Liver UP - $n(\%)$ & $11(100)$ & $10(31.3)$ & $<0.001^{\wedge}$ \\
\hline Stomach UP - $n(\%)$ & $7(63.6)$ & $18(56.3)$ & $0.736^{\wedge}$ \\
\hline Spleen UP - $n(\%)$ & $5(45.5)$ & $22(68.8)$ & $0.278^{\wedge}$ \\
\hline \multicolumn{4}{|l|}{ POSTNATAL DATA } \\
\hline Gestational age (weeks) - mean (SD) & $35.7(2.5)$ & $37.7(1.4)$ & $0.003^{*}$ \\
\hline Birthweight (g) - mean (SD) & $2,616(465)$ & $3,059(560)$ & $0.023^{*}$ \\
\hline Males - $n(\%)$ & $6(54.5)$ & $22(68.8)$ & $0.473^{\wedge}$ \\
\hline Inborn - $n(\%)$ & $11(100)$ & $29(90.6)$ & $0.558^{\wedge}$ \\
\hline Vaginal delivery - $n(\%)$ & $9(81.8)$ & $18(56.3)$ & $0.166^{\wedge}$ \\
\hline APGAR 1 min - median (IQR) & $6.5(4.75-8)$ & $6(4-8)$ & $0.939^{\circ}$ \\
\hline APGAR 5 min - median (IQR) & $8.5(7.75-9)$ & $8(8-9)$ & $0.887^{\circ}$ \\
\hline Day of surgical repair - median (IQR) & $2(2-3)$ & $2.5(2-4)$ & $0.106^{\circ}$ \\
\hline Diaphragmatic patch - $n(\%)$ & $8(72.7)$ & $10(31.3)$ & $0.031^{\wedge}$ \\
\hline Abdominal patch - $n(\%)$ & $0(0)$ & $1(9.1)$ & $0.256^{\wedge}$ \\
\hline $\begin{array}{l}\text { Mechanical ventilation (days) - median } \\
\text { (IQR) }\end{array}$ & $17(16-24)$ & $\begin{array}{c}11.5 \\
(8.25-19.75)\end{array}$ & $0.046^{\wedge}$ \\
\hline ECMO - n (\%) & $0(0)$ & $0(0)$ & - \\
\hline Lenght of stay (days) - median (IQR) & $70(43-106)$ & $41(31-57)$ & $0.012^{\circ}$ \\
\hline
\end{tabular}

Student's T-Test, Mann Whitney U-Test, or Fisher Exact Test were performed as indicated. $C D H$, congenital diaphragmatic hernia; FETO, fetal endoscopic tracheal occlusion; O/E $L H R$, observed/expected lung-to-head ratio; SD, standard deviation; IQR, interquartile range; ECMO, extracorporeal membrane oxygenation. *, Student's T-Test; ' Whitney U-Test; ^ , Fisher Exact Test.

non-FETO patients, probably due to their worse initial clinical conditions. Considering the inverse correlation between RR and $\mathrm{V}_{\mathrm{T}}$, the higher respiratory rates observed in the FETO group could represent a physiological mechanism aimed at compensating for a reduction in tidal volumes in an attempt to maintain adequate minute ventilation (31).

Finally, when considering FETO and non-FETO groups separately, the link between radiological and respiratory parameters disappeared, except for total lung area and $\mathrm{V}_{\mathrm{T}}$ in the untreated group. Probably, the limited sample size in each subgroup may have precluded the analysis from having enough power to reveal any functional differences or significant statistical associations.

While evaluating our results, a potential selection bias should be considered for the follow-up group, which includes infants who survived the acute critical phase. The study population 
A

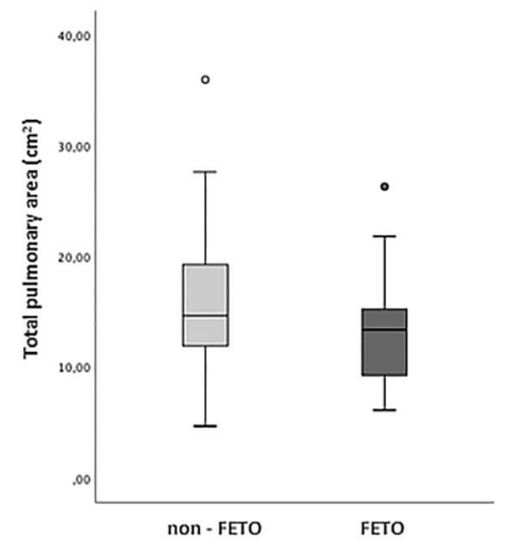

B

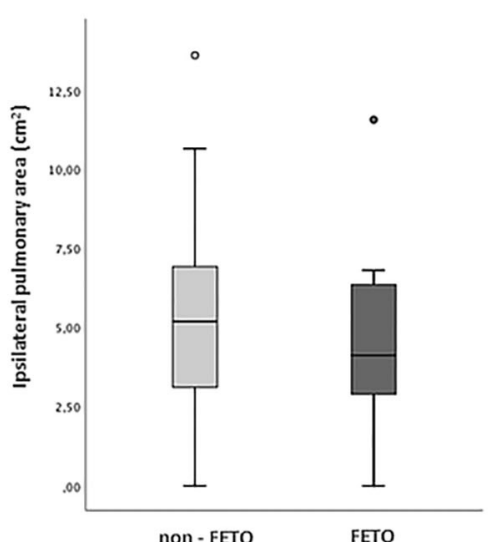

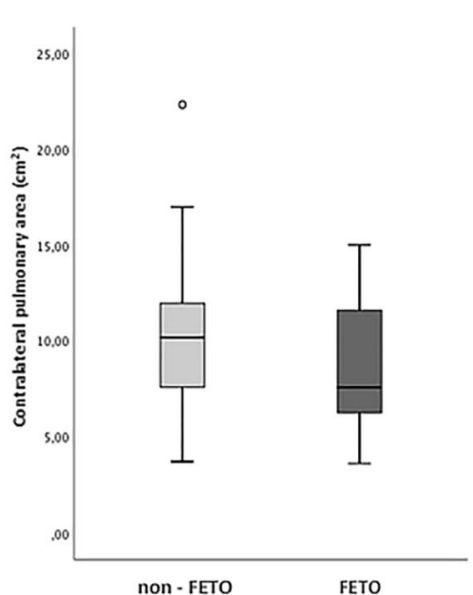

FIGURE 5 | Pulmonary Area in FETO and non-FETO groups. Boxplot showing the distribution of the radiographic measurements in FETO ( $n=11)$ and non-FETO $(n$ $=32$ ) patients. Student's $T$-Test was performed to compare the two groups. (A) total pulmonary area $\left(\mathrm{cm}^{2}\right), p=0.358 ;(\mathbf{B})$ ipsilateral pulmonary area $\left(\mathrm{cm}^{2}\right), p=$ 0.553; (C) contralateral pulmonary area $\left(\mathrm{cm}^{2}\right), p=0.306$.

A

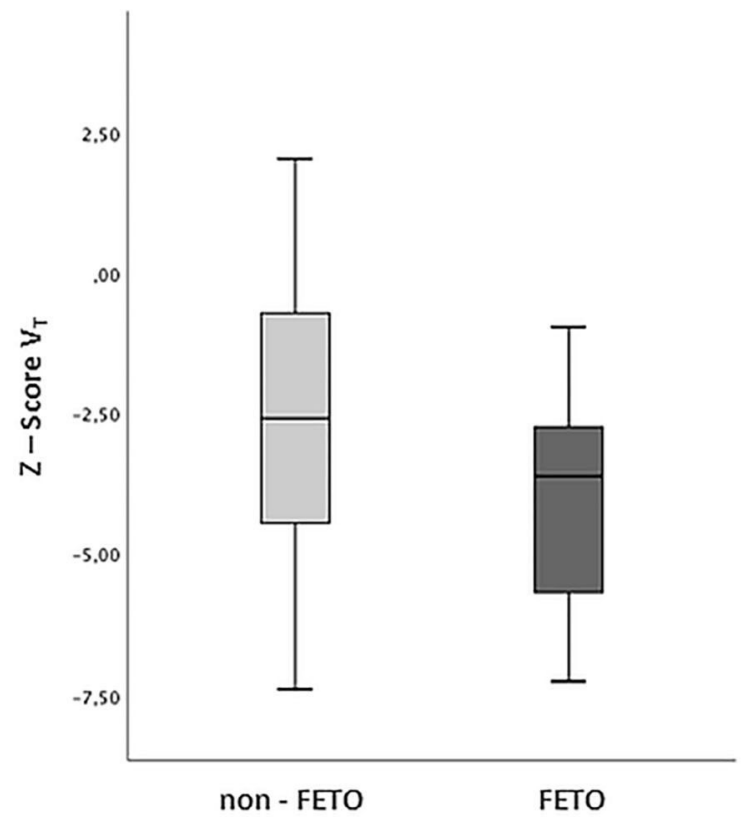

B

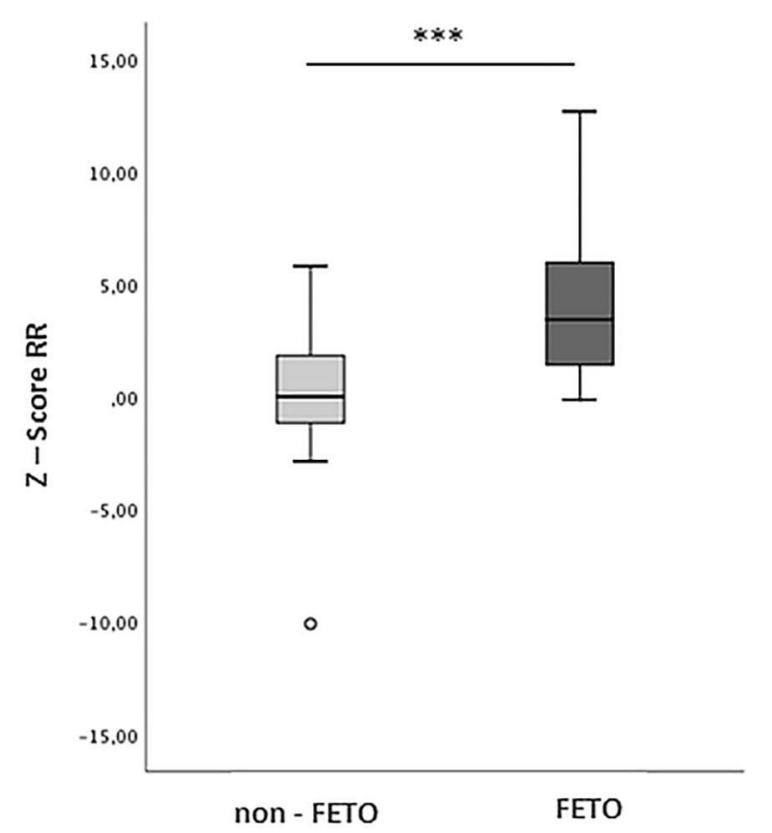

FIGURE $6 \mid V_{T}$ and RR in FETO and non-FETO groups. Boxplot showing the distribution of the respiratory parameters between FETO $(n=11)$ and non-FETO $(n=$ 32) patients. Student's $T$-Test was performed to compare the two groups. (A) Z Score Tidal Volume $\left(V_{T}\right), p=0.070$. (B) Z-Score Respiratory Rate (RR), ${ }^{\star \star *} p<0.001$.

included infants born at term with adequate gestational age, predominantly affected by mild forms of $\mathrm{CDH}$. In particular, initial hernia severity was drastically unbalanced between FETO and non-FETO groups, since the first was constituted by severe forms, while all patients presenting mild forms were included in the latter. However, O/E LHR\% before birth was even better in the FETO group, suggesting that only those with optimal response to prenatal treatment were included. Furthermore, in a recent work, Dassios et al. evaluated the chest radiographic thoracic area (CRTA) on the 1st day of life and the risk of mortality in a cohort of newborns with $\mathrm{CDH}$. According to their results, a CRTA higher than $12.99 \mathrm{~cm}^{2}$ predicted survival to discharge from neonatal care with a $85 \%$ sensitivity and $73 \%$ specificity (13). In our study, the mean total pulmonary area of the follow-up group was $14.93 \mathrm{~cm}^{2}$. Therefore, we believe that the effect of the variable "lung area" could not be wholly appreciated. 
TABLE 4 | Linear regression analysis between radiographic measurements and absolute Z-Score Tidal Volume $\left(V_{T}\right)$ or absolute Z-Score Respiratory Rate (RR) in FETO and non-FETO groups.

\begin{tabular}{|c|c|c|c|c|c|c|}
\hline & \multicolumn{3}{|c|}{ Absolute $\mathbf{Z}$-score $\mathbf{V}_{\mathbf{T}}$} & \multicolumn{3}{|c|}{ Absolute Z-score RR } \\
\hline & B & $95 \% \mathrm{Cl}$ & $p$-value & B & $95 \% \mathrm{Cl}$ & $p$-value \\
\hline \multicolumn{7}{|l|}{ Non-FETO } \\
\hline $\begin{array}{l}\text { Total pulmonary area } \\
\left(\mathrm{cm}^{2}\right)\end{array}$ & -0.11 & $\begin{array}{c}-0.21 \\
0.00\end{array}$ & 0.045 & -0.01 & $\begin{array}{c}-0.13 \\
0.11\end{array}$ & 0.824 \\
\hline $\begin{array}{l}\text { Ipsilateral pulmonary } \\
\text { area }\left(\mathrm{cm}^{2}\right)\end{array}$ & -0.20 & $\begin{array}{c}-0.42 \\
0.01\end{array}$ & 0.057 & -0.11 & $\begin{array}{c}-0.35 \\
0.12\end{array}$ & 0.331 \\
\hline $\begin{array}{l}\text { Contralateral } \\
\text { pulmonary area }\left(\mathrm{cm}^{2}\right)\end{array}$ & -0.15 & $\begin{array}{c}-0.33 \\
0.02\end{array}$ & 0.084 & 0.04 & $\begin{array}{c}-0.15 \\
0.24\end{array}$ & 0.672 \\
\hline \multicolumn{7}{|l|}{ FETO } \\
\hline $\begin{array}{l}\text { Total pulmonary area } \\
\left(\mathrm{cm}^{2}\right)\end{array}$ & -0.02 & $\begin{array}{c}-0.27 \\
0.22\end{array}$ & 0.840 & -0.06 & $\begin{array}{c}-0.52 \\
0.39\end{array}$ & 0.760 \\
\hline $\begin{array}{l}\text { Ipsilateral pulmonary } \\
\text { area }\left(\mathrm{cm}^{2}\right)\end{array}$ & -0.20 & $\begin{array}{c}-0.66 \\
0.26\end{array}$ & 0.344 & -0.35 & $\begin{array}{c}-1.22 \\
0.51\end{array}$ & 0.378 \\
\hline $\begin{array}{l}\text { Contralateral } \\
\text { pulmonary area }\left(\mathrm{cm}^{2}\right)\end{array}$ & 0.08 & $\begin{array}{c}-0.31 \\
0.47\end{array}$ & 0.669 & 0.07 & $\begin{array}{c}-0.67 \\
0.81\end{array}$ & 0.833 \\
\hline
\end{tabular}

In fact, infants with a more severe clinical condition, who did not survive until discharge, were automatically excluded from the population undergoing PFTs.

\section{Strengths and Limitations}

Even retrospective, the study seems to be the first that analyzes the radiographic pulmonary area at birth concerning a functional outcome among survivors in $\mathrm{CDH}$ patients. This could be an essential step, as the measurement is simple and easily reproducible, could be performed anywhere, and would be capable of predicting an important remote outcome.

Some limitations that are intrinsic to the retrospective nature of the study should also be considered. First, our sample size could be inadequate to analyze a complex outcome such as respiratory function and to generalize findings to a broader population. The small sample size particularly precluded us from performing further subgroup analysis. Second, PFTs were not performed at the same age in all patients, as we considered the measurements available for data collection retrospectively. Therefore, the range of observation was extended to 6-18 months of corrected age to include the highest possible number of participants. However, lung maturation continues during infancy up to early adulthood, and many studies have already reported a tendency to normalization of respiratory anomalies during the 1st years of life in $\mathrm{CDH}$ patients $(22,24,29,30)$. A regression model was developed to take into consideration most of the agerelated variations, which could affect the results. Nevertheless, 6-18 months could be a too-wide range of observation, which could hide possible differences in respiratory function during the various periods of life. A bigger sample size should allow overcoming these limits, and different steps during the child's growth should be analyzed by more comparable subgroups.

Acquired variables with a potential impact on pulmonary morbidity in $\mathrm{CDH}$ patients, such as iatrogenic lung injury induced by mechanical ventilation, respiratory infections, altered diaphragmatic curvature after surgery, thoracic wall deformities, impaired nutritional status, or growth, were not considered (4, $23,24)$. However, we felt this fell out of the scope of our study.

\section{PERSPECTIVES AND CONCLUSION}

From a future research perspective, both increasing the sample size and adding an imaging study of the airways and thoracic cage would be of interest to better define pulmonary conditions in this population. Besides, the evaluation of other factors, such as iatrogenic lung injury, infections, and growth patterns, could provide a more comprehensive view of patients' outcomes.

In conclusion, radiographic pulmonary area at birth and tidal volume at follow-up are significantly correlated in patients with CHD. The ipsilateral radiographic pulmonary area plays a significant role in determining a patient's respiratory longterm outcome as measured by PFTs. Our study suggests that pulmonary radiographic assessment at birth could be used in predicting long-term respiratory outcomes in patients with $\mathrm{CHD}$.

\section{DATA AVAILABILITY STATEMENT}

The datasets generated for this study can be found in online repositories. The names of the repository/repositories and accession number(s) can be found at: ClinicalTrials.gov: NCT04396028.

\section{ETHICS STATEMENT}

The studies involving human participants were reviewed and approved by Milan Area 2, Italy. Written informed consent to participate in this study was provided by the participants' legal guardian/next of kin.

\section{AUTHOR CONTRIBUTIONS}

IA, GC, GR, SGa, SGh, VC, MO, NPes, and FMo contributed to the conception and design of the study. IA, GR, GC, VC, SGa, SGh, and FMa wrote the first draft of the manuscript. IA, NPes, and GC calculated the sample size. NPes performed the statistical analyzes. IA and IB assessed radiographic pulmonary areas. MO performed pulmonary function tests. IB, NPer, IF, FMa, MC, and FMo provided extensive critical revision. All authors contributed to manuscript critical revision, read, and approved the submitted version.

\section{ACKNOWLEDGMENTS}

The authors would like to thank all the Neonatal ECMO Team Mangiagalli of the Fondazione IRCCS Ca' Granda Ospedale Maggiore Policlinico: nurses and neonatologists of the NICU, surgeons of the Department of Pediatric Surgery, anesthesiologists of the Pediatric Anesthesiology and Intensive Care Unit, nurses of the operating room. 


\section{REFERENCES}

1. Gleason CA, Devaskar SU. Avery's Diseases of the Newborn. 9th ed. Philadephia: Elsevier Saunders (2012). p. 571-83.

2. Deprest J, Brady P, Nicolaides K, Benachi A, Berg C, Vermeesch J, et al. Prenatal management of the fetus with isolated congenital diaphragmatic hernia in the era of the TOTAL trial. Semin Fetal Neonatal Med. (2014) 19:338-48. doi: 10.1016/j.siny.2014.09.006

3. Pierro M, Thébaud B. Understanding and treating pulmonary hypertension in congenital diaphragmatic hernia. Semin Fetal Neonatal Med. (2014) 19:35763. doi: 10.1016/j.siny.2014.09.008

4. American Academy of Pediatrics Section on Surgery, American Academy of Pediatrics Committee on Fetus and Newborn. Postdischarge follow-up of infants with congenital diaphragmatic hernia. Pediatrics. (2008) 121:62732. doi: 10.1542/peds.2007-3282

5. Stocks J, Sly PD, Morris M., Frey U. Standards for infant respiratory function testing: what(ever) next? Eur Respir J. (2000) 16:581. doi: 10.1034/j.1399-3003.2000.16d01.x

6. Stocks J, Godfrey S, Beardsmore C, Bar-Yishay E, Castile R. Plethysmographic measurements of lung volume and airway resistance. Eur Respir J. (2001) 17:302-12. doi: 10.1183/09031936.01.17203020

7. Wauer RR, Maurer T, Nowotny T, Schmalisch G. Assessment of functional residual capacity using nitrogen washout and plethysmographic techniques in infants with and without bronchopulmonary dysplasia. Intensive Care Med. (1998) 24:469-75. doi: 10.1007/s001340050598

8. Dimitriou G, Greenough A, Kavvadia V, Shute M, Karani J. A radiographic method for assessing lung area in neonates. Br J Radiol. (1999) 72:3358. doi: 10.1259/bjr.72.856.10474492

9. Dimitriou G, Greenough A. Computer assisted analysis of the chest radiograph lung area and prediction of failure of extubation from mechanical ventilation in preterm neonates. Br J Radiol. (2000) 73:1569. doi: 10.1259/bjr.73.866.10884728

10. May C, Prendergast M, Salman S, Rafferty GF, Greenough A. Chest radiograph thoracic areas and lung volumes in infants developing bronchopulmonary dysplasia. Pediatr Pulmonol. (2009) 44:80-5. doi: 10.1002/ppul.20952

11. Dassios T, Curley A, Krokidis M, Morley C, Ross-Russell R. Correlation of radiographic thoracic area and oxygenation impairment in bronchopulmonary dysplasia. Respir Physiol Neurobiol. (2016) 220:40-5. doi: 10.1016/j.resp.2015.09.009

12. Dimitriou G, Greenough A, Davenport M, Nicolaides K. Prediction of outcome by computer-assisted analysis of lung area on the chest radiograph of infants with congenital diaphragmatic hernia. J Pediatr Surg. (2000) 35:48993. doi: 10.1016/S0022-3468(00)90219-7

13. Dassios T, Ali K, Makin E, Bhat R, Krokidis M, Greenough A. Prediction of mortality in newborn infants with severe congenital diaphragmatic hernia using the chest radiographic thoracic area. Pediatr Crit Care Med. (2019) 20:534-9. doi: 10.1097/PCC.0000000000001912

14. Van der Veeken L, Russo FM, De Catte L, Gratacos E, Benachi A, Ville $\mathrm{Y}$, et al. Fetoscopic endoluminal tracheal occlusion and reestablishment of fetal airways for congenital diaphragmatic hernia. Gynecol Surg. (2018) 15:9. doi: 10.1186/s10397-018-1041-9

15. Snoek KG, Reiss IKM, Greenough A, Capolupo I, Urlesberger B, Wessel L, et al. Standardized postnatal management of infants with congenital diaphragmatic hernia in Europe: the CDH EURO consortium consensus - 2015 Update. Neonatology. (2016) 110:66-74. doi: 10.1159/000 444210

16. Hollinger LE, Buchmiller TL. Long term follow-up in congenital diaphragmatic hernia. Semin Perinatol. (2020) 44:151171. doi: 10.1053/j.semperi.2019.07.010

17. Nguyen TTD, Hoo A-F, Lum S, Wade A, Thia LP, Stocks J. New reference equations to improve interpretation of infant lung function. Pediatr Pulmonol. (2013) 48:370-80. doi: 10.1002/ppul.22656

18. Van Den Hout L, Schaible T, Cohen-Overbeek TE, Hop W, Siemer J, Van De Ven K, et al. Actual outcome in infants with congenital diaphragmatic hernia: the role of a standardized postnatal treatment protocol. Fetal Diagn Ther. (2011) 29:55-63. doi: 10.1159/000322694

19. Zalla JM, Stoddard GJ, Yoder BA. Improved mortality rate for congenital diaphragmatic hernia in the modern era of management: 15 year experience in a single institution. J Pediatr Surg. (2015) 50:524-7. doi: 10.1016/j.jpedsurg.2014.11.002

20. Doyle NM, Lally KP. The CDH study group and advances in the clinical care of the patient with congenital diaphragmatic hernia. Semin Perinatol. (2004) 28:174-84. doi: 10.1053/j.semperi.2004.03.009

21. Rygl M, Rounova P, Sulc J, Slaby K, Stranak Z, Pycha K, et al. Abnormalities in pulmonary function in infants with high-risk congenital diaphragmatic hernia. Biomed Pap. (2015) 159:497-502. doi: 10.5507/bp.2015.040

22. Dotta A, Palamides S, Braguglia A, Crescenzi F, Ronchetti MP, Calzolari F, et al. Lung volumes and distribution of ventilation in survivors to Congenital Diaphragmatic Hernia (CDH) during infancy. Pediatr Pulmonol. (2007) 42:600-4. doi: 10.1002/ppul.20609

23. Roehr CC, Proquitté H, Jung A, Ackert U, Bamberg C, Degenhardt $\mathrm{P}$, et al. Impaired somatic growth and delayed lung development in infants with congenital diaphragmatic hernia-evidence from a 10 -year, single center prospective follow-up study. J Pediatr Surg. (2009) 44:130914. doi: 10.1016/j.jpedsurg.2008.10.047

24. Koumbourlis AC, Wung JT, Stolar CJ. Lung function in infants after repair of congenital diaphragmatic hernia. J Pediatr Surg. (2006) 41:171621. doi: 10.1016/j.jpedsurg.2006.05.044

25. Arena F, Romeo C, Calabrò MP, Antonuccio P, Arena S, Romeo G. Long-term functional evaluation of diaphragmatic motility after repair of congenital diaphragmatic hernia. J Pediatr Surg. (2005) 40:107881. doi: 10.1016/j.jpedsurg.2005.03.058

26. Laviola M, Zanini A, Priori R, Macchini F, Leva E, Torricelli M, et al. Thoracoabdominal asymmetry and asynchrony in congenital diaphragmatic hernia. Pediatr Pulmonol. (2015) 50:915-24. doi: 10.1002/ppul.23081

27. Khirani S, Amaddeo A, Khen-Dunlop N, Arroyo JO, Lapillonne A, Becquet $\mathrm{O}$, et al. Diaphragmatic function in infants and children with congenital diaphragmatic hernia: A cross-sectional study. Eur J Cardiothoracic Surg. (2018) 53:740-7. doi: 10.1093/ejcts/ezx391

28. Morandi A, Macchini F, Ophorst M, Borzani I, Ciralli F, Farolfi A, et al. Tracheal diameter and respiratory outcome in infants with congenital diaphragmatic hernia treated by fetal endoscopic tracheal occlusion. Fetal Diagn Ther. (2018) 46:296-305. doi: 10.1159/000491785

29. Narayanan M, Beardsmore CS, Owers-Bradley J, Dogaru CM, Mada M, Ball I, et al. Catch-up alveolarization in ex-preterm children: evidence from 3He magnetic resonance. Am J Respir Crit Care Med. (2013) 187:11049. doi: 10.1164/rccm.201210-1850OC

30. Carraro S, Filippone M, Da Dalt L, Ferraro V, Maretti M, Bressan S, et al. Bronchopulmonary dysplasia: the earliest and perhaps the longest lasting obstructive lung disease in humans. Early Hum Dev. (2013) 89(Suppl 3):S35. doi: 10.1016/j.earlhumdev.2013.07.015

31. Keszler M, Abubakar K. Physiologic Principles. In: Goldsmith JP, Karotkin EH, Keszler M, Suresh GK, editors. Assisted Ventilation of the Neonate: An Evidence-Based Approach to Newborn Respiratory Care. 6th ed. Philadelphia: Elsevier. (2017). p. 8-30. doi: 10.1016/B978-0-323-39006-4.00002-8

Conflict of Interest: The authors declare that the research was conducted in the absence of any commercial or financial relationships that could be construed as a potential conflict of interest.

Copyright $\odot 2020$ Amodeo, Raffaeli, Pesenti, Macchini, Condò, Borzani, Persico, Fabietti, Ophorst, Ghirardello, Gangi, Colnaghi, Mosca and Cavallaro. This is an open-access article distributed under the terms of the Creative Commons Attribution License (CC BY). The use, distribution or reproduction in other forums is permitted, provided the original author $(s)$ and the copyright owner(s) are credited and that the original publication in this journal is cited, in accordance with accepted academic practice. No use, distribution or reproduction is permitted which does not comply with these terms. 